\title{
Trauma-informed interventions versus control for cancer-risk behaviours among adults: rationale and design for a randomized trial
}

Cheryl L. Currie ${ }^{1 *}$ D, Jennifer L. Copeland ${ }^{2}$, M. Lauren Voss², Lisa-Marie Swanepoel ${ }^{1}$, Mirela Ambeskovic ${ }^{3}$, Nimesh B. Patel ${ }^{1}$ and Erin K. Higa ${ }^{1}$

\begin{abstract}
Background: Tobacco use, alcohol use, and sugar-sweetened beverage consumption are each associated with increased cancer-risk. Psychological trauma is a common experience and a key driver of these behaviours among adults. The primary aim of this study is to evaluate the effect of trauma-informed yoga, drumming, and psychoeducation compared to control on tobacco use, alcohol use, and sugar-sweetened beverage consumption among community-based adults. Secondary aims are to evaluate the effect of these interventions compared to control on psychological and physiological stress symptomology, social connection, and coping behaviour.
\end{abstract}

Methods: Recruitment for this single-blinded randomized trial began in April 2019 in the Faculty of Health Sciences at the University of Lethbridge. Adults who consumed tobacco, alcohol, or sugar-sweetened beverages in the past month and live in Lethbridge, Alberta are being recruited using ads placed in public spaces. Participants are randomly allocated to a 12-session group yoga class, 12-session group drumming class, a 12-session psychoeducation class, or control. Participants attend an appointment in-person to fill out an online questionnaire package, provide a saliva sample, and complete physical measures pre-intervention, and 1-month and 6-months post-intervention.

Discussion: This study provides a unique opportunity to compare the impacts of two trauma-informed body-based interventions to psychoeducation and control for cancer-risk behaviour among community-based adults. The findings can be used to develop trauma-informed group interventions to reduce cancer-risk behaviour in general populations. Results are expected in 2022.

Trial registration: This trial was registered with ClinicalTrials.gov ISRCTN15583681 on 22 August 2019 (retrospectively registered).

Keywords: Cancer-risk behaviour, Smoking, Alcohol, Yoga, Drumming, Psychoeducation

\footnotetext{
* Correspondence: cheryl.currie@uleth.ca

${ }^{1}$ Faculty of Health Sciences, University of Lethbridge, M3083 Markin Hall,

4401 University Drive, Lethbridge, AB T1K 3M4, Canada

Full list of author information is available at the end of the article
}

(c) The Author(s). 2019 Open Access This article is distributed under the terms of the Creative Commons Attribution 4.0 International License (http://creativecommons.org/licenses/by/4.0/), which permits unrestricted use, distribution, and reproduction in any medium, provided you give appropriate credit to the original author(s) and the source, provide a link to the Creative Commons license, and indicate if changes were made. The Creative Commons Public Domain Dedication waiver (http://creativecommons.org/publicdomain/zero/1.0/) applies to the data made available in this article, unless otherwise stated. 


\section{Background}

Well established cancer-risk behaviours include smoking and alcohol use. The association between tobacco use and the development of various cancers is strong, dosedependent and insensitive to covariate-adjustment, with systematic reviews demonstrating that smoking considerably enhances and cessation delays the risk of developing and dying of cancer [1-5]. Causal relationships between alcohol consumption and cancer of the oral cavity, pharynx, larynx, esophagus, liver, colorectum and breast are well established, with relative risks rising in a dose-response fashion with increasing alcohol consumption for all named sites [6-10]. There is no safe threshold of alcohol intake for cancer risk [9, 11, 12]. Alcohol is a major contributor to cancer mortality and years of potential life lost due to cancer. The habitual consumption of sugar-sweetened beverages is an emerging risk factor for cancer associated with the increased incidence of pancreatic, gallbladder and biliary tract cancer; with cancer reoccurrence and mortality generally; and with important risk factors for cancer (e.g., type 2 diabetes, obesity) [13-17].

Much of the effort to prevent cancer-risk behaviours have been based on the theory that lack of knowledge is a key driver. Thus, mass media campaigns have been a central focus for prevention efforts [18]. Yet, despite the enormous amount of resources invested, a recent systematic review of reviews found limited evidence that mass media campaigns have an impact on alcohol use and diet, and mixed evidence for impacts on tobacco use [19]. To make progress, there is a need to move beyond the assumption that cancer-risk behaviours are wholly determined by individual susceptibility due to lack of knowledge. We must also consider population susceptibility due to common agents present within the social milieu in which we grow, live, work and age [20].

\section{Social trauma and cancer-risk behaviour}

Humans are naturally inclined to establish and maintain profound bonds within society [21]. Factors that interfere with this natural process such as adverse childhood experiences (ACEs) have been shown to increase cancerrisk behaviour. A review of 155 quantitative, peerreviewed US studies indicates adults will use the psychoactive properties of nicotine and alcohol, or may engage in emotional eating and/or excessive sugar consumption to manage the dysphoria associated with ACEs [22]. ACEs include physical, emotional and sexual abuse; emotional and physical neglect; and/or household dysfunction experienced before 18 years of age (i.e., domestic violence, mental illness and addiction in the household, parental separation and parental incarceration) [23].

In North America exposure to ACEs is common with the majority of adults reporting at least one ACE (52-67\%), two ACEs (26-42\%), and up to as many as four or more ACEs (6-16\%) by the age of 18 years [23-28]. In Canada, the prevalence of ACEs and other forms of social trauma may be further elevated among Indigenous adults given child maltreatment was a common experience in residential school up until the last school closed in 1996, and Indigenous adults also report high levels of racial discrimination and social exclusion across the life course [29-32].

\section{Interventions}

In North America, there is a strong focus on the verbal narrative in psychological and psychiatric treatment. Yet the rational, executive brain has been shown to have limited capacity to control emotional and physiological arousal in response to trauma triggers [33]. Specifically, the autonomic nervous system interferes with executive function once sensory triggers of past trauma activate the brain to engage in habitual, self-protective behaviour [34]. Compounding this problem, decreased activation of the medial prefrontal cortex among individuals who have experienced trauma makes it more difficult to become aware of these internal states, and when they are being activated [35]. Further, many traumatized individuals have also learned to disassociate from the body as a form of selfprotection [36, 37]. Thus, it may be more difficult to remain aware of, or concerned about, the ways in which tobacco use, alcohol use, and sugar-sweetened beverage consumption are affecting the physical body. Body-oriented interventions designed to increase awareness of physical sensations, muscle activation, and the movement of the body may offer the opportunity to reprogram automatic physiologic hyperarousal in response to triggers, while at the same time increasing positive body awareness, and mindful attention to the ways in which various habitual self-protective behaviours may be impacting physical health.

Given most traumatic experiences occur in the context of interpersonal relationships, the resulting boundary violations and loss of autonomous action can interfere with the ability to form trusting relationships with others [38]. Alexander has posited that such experiences result in social dislocation, defined as an enduring lack of psychosocial integration in society, an experience that is both individually painful and socially destructive [21]. From this perspective, engaging in cancer-risk behaviour may be a way of adapting to the discomfort of sustained social dislocation by providing the rewards an individual would normally receive through their social world. Group interventions designed to build social trust may be effective in reducing these behaviours.

The premise for this study is that adults in Canada are susceptible to cancer-risk behaviour due to the pervasiveness of ACEs and other forms of social trauma within society, and that addressing the psychological symptomology, physiologic sequelae, and social dislocation associated with 
interpersonal trauma may reduce cancer-risk behaviour and increase healthy coping behaviour. We will examine this premise by comparing three 12-session interventions that have been designed to emphasize the connection between mind and body and build group trust, to control on three primary endpoints (tobacco use, alcohol use, and sugar-sweetened beverage consumption). We will also examine changes in four secondary endpoints (psychological stress symptomology, physiological stress symptomology, social dislocation, and coping behaviour choices).

Trauma-informed yoga. Twelve group yoga sessions, delivered weekly, will use breathing exercises, physical postures, and mindfulness meditation to direct participant attention toward internal states and the connection between mind and body [39]. Yoga has been shown to impact both psychological and physiological sequelae associated with trauma [40-42]. It has been theorized that trauma-informed yoga (TIY) that emphasizes choice, as well as curiosity about bodily sensations may strengthen these impacts $[39,43]$. In the present study, licensed yoga instructors with TIY training will guide participants using language modified to reduce the likelihood it may trigger traumatic memories. Invitatory language will encourage participants to make choices (e.g., when you are ready, I invite you to experiment with lifting your arms), and reflect on how the movements and breathing they choose to engage in resonates within their body (e.g., you might consider what it feels like to stretch your calf in this way).

Trauma-informed drumming. Twelve group drumming sessions, delivered weekly, will offer a patterned, repetitive, rhythmic experience that can be effective in regulating the brainstem and neural network among adults who have experienced trauma. At a psychological level, group drumming has been shown to improve mood and reduce trauma-related symptoms including PTSD, anxiety, and impulsivity; and promote self-expression, social cohesion, and engagement in treatment [44-46]. At a physiologic level, group drumming that emphasizes camaraderie, group acceptance, and nonjudgmental performance has been shown to attenuate physiological stress response patterns, resulting in statistically significant increases in plasma dehydroepiandrosterone-to-cortisol ratios, natural killer cell activity, lymphocyte-activated killer cell activity; as well as improve pain tolerance; and decreased blood pressure and inflammation [47-52]. In this study, group drumming will be delivered using trauma-informed, invitatory language. Participants will be invited to engage various drums and rhythms, and to reflect on how these sensations resonate within their body.

Trauma-informed psychoeducation. Twelve group psychoeducation sessions, delivered weekly, will be delivered using trauma-informed, invitatory language. Licensed counsellors will teach adults about various forms of social trauma, how these experiences impact the body and mind, and ways to respond to and cope with stress in healthy ways.

\section{Methods/design \\ Objectives}

The primary objective is to evaluate the effect of traumainformed group yoga, drumming, and psychoeducation compared to one another and control on tobacco use, alcohol use, and sugar-sweetened beverage consumption among community-based adults.

Secondary objectives are to evaluate the effect of traumainformed group yoga, drumming, and psychoeducation compared to one another and control on several outcomes including: (1) psychological stress symptomology, (2) physiologic stress symptomology, (3) social dislocation, and (4) health coping behaviour among community-based adults.

\section{Trial design and study setting}

The CRIS (Cancer-Risk Interventions Study) trial is a parallel, 4-arm randomized controlled trial with blinding of assessors. The study was approved by the Human Research Ethics Board of Alberta Cancer Committee. The trial started in April 2019 led by Dr. Cheryl Currie in the Faculty of Health Sciences at the University of Lethbridge in Alberta, Canada. The trial is expected to end in late 2021. Participation in each condition will last approximately 44 weeks (8 weeks prior to the intervention to complete baseline data collection with all participants, 12 weeks for the intervention, and 24 weeks post-intervention). A schedule of the CRIS trial is provided in Table 1.

\section{Participant and public involvement}

Over an 18-month period beginning in June 2017 and ending December 2018, we received input from mental health professionals, members of the public, and Indigenous Elders and stakeholders who have expertise in and/or have struggled with psychological trauma or cancer-risk behaviour. Based on these consultations we will oversample Indigenous adults for each study arm and interventions will be run separately for males and females. Participants will also be provided the opportunity to have their saliva samples returned to them or included in a ceremony led by an Indigenous Elder to return them to the Earth, in keeping with Indigenous cultural protocols in our territory.

\section{Eligibility criteria}

The study is recruiting a community-based sample of 400 adults that meet eligibility criteria to achieve 300 participants (approximately 25\% loss-to-follow-up, $n=$ 75 per arm, see Fig. 1). 
Table 1 Participant timeline

\begin{tabular}{|c|c|c|c|c|c|c|}
\hline \multirow[t]{3}{*}{ Item } & \multirow[t]{3}{*}{ Instrument } & \multicolumn{5}{|l|}{ Study Period } \\
\hline & & \multirow{2}{*}{$\begin{array}{l}\text { Enrollment } \\
\mathrm{T}_{0} \\
\end{array}$} & \multirow{2}{*}{$\begin{array}{l}\text { Baseline } \\
\text { Assessment/ } \\
\text { Allocation } \\
\mathrm{T}_{1} \\
\end{array}$} & \multirow{2}{*}{$\begin{array}{l}\text { Post-Allocation } \\
12 \text {-Week } \\
\text { Intervention } \\
\mathrm{T}_{2} \\
\end{array}$} & \multirow{2}{*}{$\begin{array}{l}\text { Follow-up } \\
1 \text { month } \\
F_{1}\end{array}$} & \multirow{2}{*}{$\begin{array}{l}\text { Follow-up } \\
6 \text { months } \\
\mathrm{F}_{2}\end{array}$} \\
\hline & & & & & & \\
\hline Eligibility screen & $\mathrm{N} / \mathrm{A}$ & $x$ & & & & \\
\hline Informed consent & N/A & & $x$ & & & \\
\hline Allocation & N/A & & $x$ & & & \\
\hline \multicolumn{7}{|l|}{ Primary outcomes } \\
\hline 1. Smoking & 4 items; salivary cotinine & & $x$ & & $x$ & $x$ \\
\hline 2. Alcohol use & AUDIT & & $x$ & & $x$ & $x$ \\
\hline 3. Sugar beverage use & 3 items & & $x$ & & $x$ & $x$ \\
\hline \multicolumn{7}{|l|}{ Secondary outcomes } \\
\hline \multicolumn{7}{|c|}{ 1. Psychological stress symptomology } \\
\hline PTSD & PTSD Checklist & & $x$ & & $x$ & $x$ \\
\hline Dissociative experiences & BDE-S & & $x$ & & $x$ & $x$ \\
\hline Depression & 2 items & & $x$ & & $x$ & $x$ \\
\hline Suicide & 2 items & & $x$ & & $x$ & $x$ \\
\hline Complicated grief & BGQ & & $x$ & & $x$ & $x$ \\
\hline Self-esteem & RSES & & $x$ & & $x$ & $x$ \\
\hline Self-compassion & SCS-SF & & $x$ & & $x$ & $x$ \\
\hline Resilience & CD-RISC & & $x$ & & $x$ & $x$ \\
\hline \multicolumn{7}{|l|}{ 2. Physiologic stress symptomology } \\
\hline Neuroendocrine & Salivary DHEA-S & & $x$ & & $x$ & $x$ \\
\hline Metabolic & BMI, waist circumference & & $x$ & & $x$ & $x$ \\
\hline Cardiovascular & $\begin{array}{l}\text { Blood pressure, heart rate, } \\
\text { uric acid }\end{array}$ & & $x$ & & $x$ & $x$ \\
\hline Immune & $\begin{array}{l}\text { Salivary markers: IgA, CRP, } \\
\text { Interleukins IL-1 } \beta, \text { IL-6, IL-8, TNF-a }\end{array}$ & & $x$ & & $x$ & $x$ \\
\hline General health & 14 items & & & & $x^{a}$ & $x^{a}$ \\
\hline \multicolumn{7}{|l|}{ 3. Social dislocation } \\
\hline Social support & SSQ & & $x$ & & $x$ & $x$ \\
\hline Community connectedness & $\mathrm{Vl}$ & & $x$ & & $x$ & $x$ \\
\hline \multicolumn{7}{|l|}{ 4. Coping behaviour } \\
\hline Physical activity & IPAQ & & $x$ & & $x$ & $x$ \\
\hline Sedentary behaviour & IPAQ & & & & $x$ & $x$ \\
\hline Sleep behaviour & PSQI & & $x$ & & $x$ & $x$ \\
\hline Eating habits & 7 items & & $x$ & & $x$ & $x$ \\
\hline Drug use /dependence & DUDIT & & $x$ & & $x$ & $x$ \\
\hline \multicolumn{7}{|l|}{ Covariates } \\
\hline \multicolumn{7}{|l|}{ 1. Social trauma } \\
\hline Childhood adversity & ACE Survey & & $x$ & & & \\
\hline Racial discrimination & EOD Scale & & $x$ & & & \\
\hline $\begin{array}{l}\text { Indigenous residential } \\
\text { school attendance }\end{array}$ & 4 items & & $x$ & & & \\
\hline Foster care/adoption & 2 items & & $x$ & & & \\
\hline
\end{tabular}


Table 1 Participant timeline (Continued)

\begin{tabular}{|c|c|c|c|c|c|c|}
\hline \multirow[t]{3}{*}{ Item } & \multirow[t]{3}{*}{ Instrument } & \multicolumn{5}{|l|}{ Study Period } \\
\hline & & Enrollment & $\begin{array}{l}\text { Baseline } \\
\text { Assessment/ } \\
\text { Allocation }\end{array}$ & $\begin{array}{l}\text { Post-Allocation } \\
12 \text {-Week } \\
\text { Intervention }\end{array}$ & $\begin{array}{l}\text { Follow-up } \\
1 \text { month }\end{array}$ & $\begin{array}{l}\text { Follow-up } \\
6 \text { months }\end{array}$ \\
\hline & & $\mathrm{T}_{0}$ & $\mathrm{~T}_{1}$ & $T_{2}$ & $F_{1}$ & $\mathrm{~F}_{2}$ \\
\hline Domestic violence & 5 items & & $x$ & & & \\
\hline Historical loss & HLS & & $x$ & & & \\
\hline 2. Sociodemographics & & & $x$ & & $x$ & $x$ \\
\hline \multicolumn{7}{|l|}{ Group Interventions } \\
\hline \multicolumn{7}{|l|}{ Yoga } \\
\hline Drumming & & & & $x$ & & \\
\hline Psychoeducation & & & & $x$ & & \\
\hline Control & & & & $x$ & & \\
\hline
\end{tabular}

${ }^{a}$ Health questions relevant for salivary measures will be asked at $F_{1}$ and $F_{2}$ (e.g., pregnancy, having a cold or flu, dental work/care). $T_{0}$, baseline; $T_{1}$, intervention allocation; $T_{2}, 12$ week intervention for those not randomized to control; $F_{1}$, first follow up appointment 1 month after intervention completion; $F_{2}$, second follow up appointment 6 months after intervention completion; AUDIT Alcohol Use Disorders Test, DUDIT Drug Use Disorders Test, IPAQ International Physical Activity Questionnaire - Short Form, HPA Axis Hypothalamic Pituitary Adrenal Axis, DHEA-S Dehydroepiandrosterone sulfate, BDE-S Brief Dissociative Experiences Scale, RSES Rosenberg Self-esteem Scale, SCS-SF Self-compassion scale - short form, PSQI Pittsburgh Sleep Quality Index, CRP C-Reactive Protein, BMI Body Mass Index, ACEs Adverse Childhood Experiences Scale, EOD Experiences of Discrimination Scale, BGQ Brief Grief Questionnaire, SSQ Social Support Questionnaire, HLS Historical Loss Scale, VI Vancouver Index

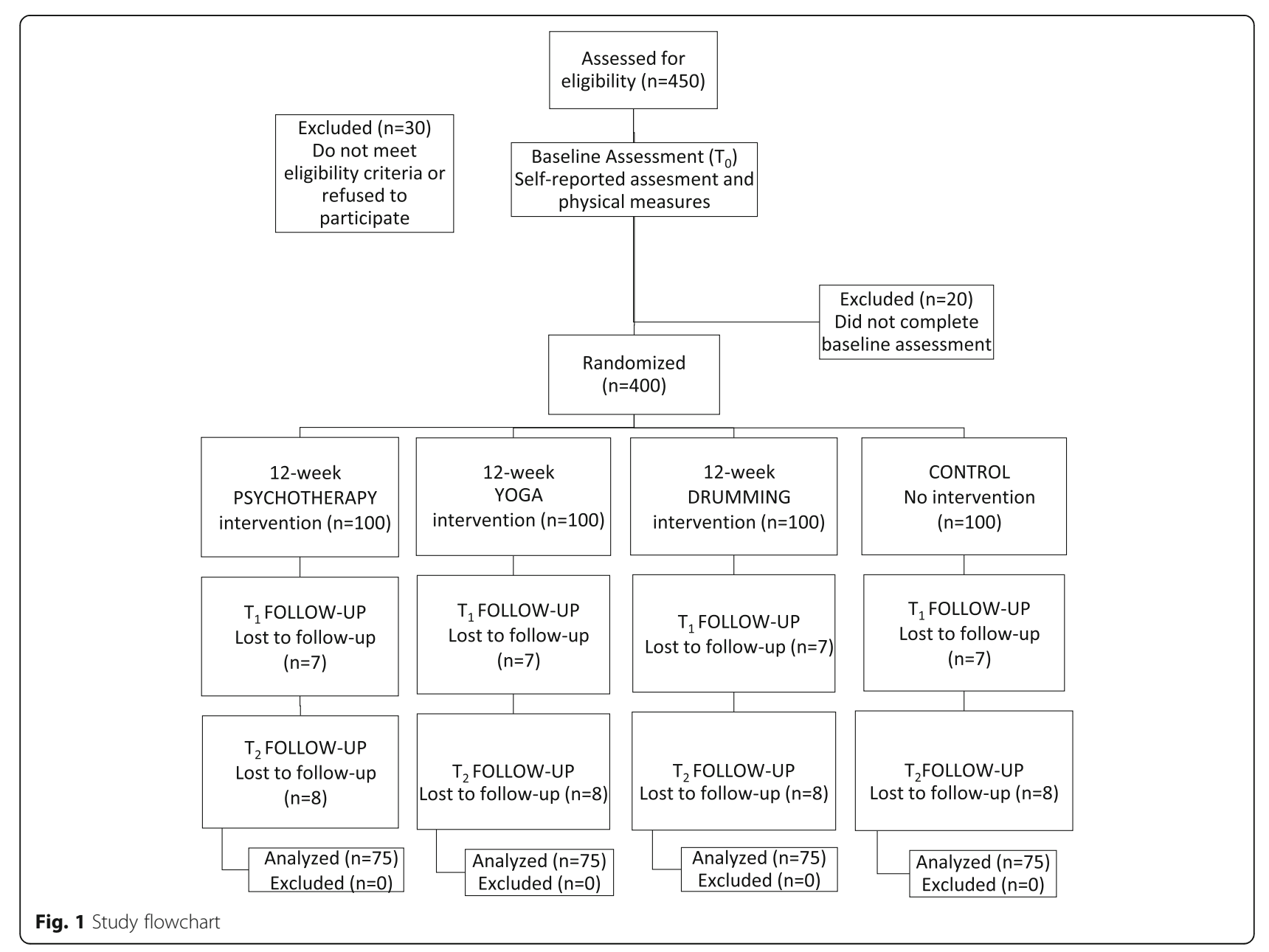




\section{Inclusion criteria}

Participants must satisfy the following criteria to be enrolled in the study:

- Aged 18 and over;

- Used a nicotine-containing substance, consumed alcohol, or consumed a sugar-sweetened beverage at least once in the past month;

- Live at a permanent address in the target city; and

- Plan to live in the target city for the next 12 months.

\section{Exclusion criteria}

Participants meeting any of the following criteria will be excluded from the study:

- Unwilling to give consent

- Lacking capacity to give consent

\section{Participant screening, recruitment and consent}

Participants are being recruited using posters placed in public spaces. We seek to oversample Indigenous adults so that stratified analyses can take place, thus some ads are specifically being placed within Indigenous organizations and agencies in the target city. Those interested are asked to contact the study coordinator. Screening and study enrollment is conducted during this phone call, text or email communication. Those eligible are scheduled to attend an appointment with two research team members (i.e., assessors) to complete informed consent and baseline measures (expected mean completion time $=75 \mathrm{~min})$ during standard office hours $(9: 00$ am $-4: 00 \mathrm{pm})$. To strengthen enrollment, improve adherence and reduce loss-to-follow-up participants will receive a $\$ 25$ gift card for attending this appointment, and all subsequent components of the study they take part in (e.g., each intervention session and data collection appointment they attend).

\section{Assignment of interventions}

Unassigned participant IDs were randomly allocated by two team members (LV, LS) to one of four conditions generated using permuted blocks of four using https:// www.randomizer.org/. The intervention that an ID was assigned was placed in a sealed envelope and kept in the main study lab. Participant IDs are being assigned consecutively as participants are enrolled. When the participant leaves the data collection appointment, they receive the envelope with information on the intervention they have been assigned including the date, time and location; and contact information for the coordinator leading the intervention they have been assigned to, who will send them a reminder before the intervention begins.

Assessors remain blinded to the allocation of the participant during baseline data collection. Participants are asked not to communicate with the assessors about the intervention received. At the two remaining data collection timepoints we will examine the success of assessor blinding by asking whether the assessor thought the participant had been allocated to a specific arm of the trial, including the percentage of certainty. (i.e., $50 \%$ would be interpreted as a pure guess). No project team member can change the group a participant has been assigned to. Team members performing statistical analyses will also be blinded to the allocation of participants.

\section{Interventions}

Participants will engage in one of four conditions. For each intervention arm, weekly sessions will take approximately 90-120 min. All spaces selected for interventions are comparable in terms of room accessibility, size, natural light, and configuration.

\section{Trauma-informed yoga}

Group yoga will be delivered once a week for 12 weeks by two licensed yoga instructors who have completed training in trauma-informed yoga delivery (approximately 25 participants per class). Each session will begin with an invitation to sit in a semi-circle facing the instructors on a yoga mat or chair placed behind a mat. Participants can engage in the class from the mat or chair or move between them as the class unfolds. One instructor will lead the class from the mat, while the second will silently demonstrate the same practice using the chair. The instructor will begin the class by introducing the week's theme (e.g., grounding and safety, centering, non-attachment, imprints of the past, connection to nature) $(10 \mathrm{~min})$, followed by a breath practice (10 $\mathrm{min})$, a yoga practice $(50 \mathrm{~min})$, a meditation practice (10 $\mathrm{min})$, and closing words (10 $\mathrm{min})$.

\section{Trauma-informed drumming}

Group drumming will be delivered once a week for 12 weeks by two instructors certified to deliver the Integrative Drum Circles (IDC) method (approximately 25 participants per class) $[53,54]$. Each session will begin with an invitation to sit on a chair beside a drum arranged in a semi-circle facing the instructors. One instructor will lead the class, while the second instructor will silently demonstrate the same practice for participants. An instructor will begin the class by introducing the week's theme (e.g., respect, gratefulness, gentleness) (10 min), followed by a drum practice using the IDC method (70 $\mathrm{min})$, and closing words (10 $\mathrm{min})$.

\section{Trauma-informed psychoeducation}

Group psychoeducation will be delivered once a week for 12 weeks by two licensed and experienced counsellors (approximately 12-13 participants per class, with 
two separate sessions running each week as 25 is too many to accommodate at one time for this intervention). Each session will begin with an invitation to sit on a chair arranged in a semi-circle facing the facilitators. One facilitator will lead the session each week. The facilitator will begin the class by introducing the week's theme (e.g., setting goals, being mindful) (10 min), followed by a lecture and activities to integrate learning (e.g., group discussion, journaling) (70 min), and closing words (10 $\mathrm{min})$.

\section{Control}

The control group will not receive an intervention.

\section{Criteria for discontinuation}

Participants who miss $50 \%$ of the intervention they are assigned to will meet criteria for discontinuation of the trial.

\section{Fidelity}

The extent to which each intervention adheres to the program model developed for it will be assessed by research staff present at the session who will record the amount of program content delivered for a specific session, adherence to program content, and the quality of delivery. Facilitators will also be asked to reflect on program fidelity for a given session when it ends using a prepared checklist with space for open-ended reflection.

\section{Outcomes}

Primary and secondary outcomes will be assessed at baseline, within 1-month post-intervention, and again 6 months post-intervention. The three primary outcomes are smoking, alcohol and sugar-sweetened beverage use. Smoking will be assessed by a change in the number of cigarettes smoked per day or per week, as measured by self-report, and changes in salivary cotinine which is a biochemical measure of active smoking and smokeless tobacco use [55]. Saliva samples will be collected during the first office visit at 3 time points using the passive drool technique. Participants will be asked to rinse their mouth with bottled water upon arrival and the first sample will be collected after completion of the demographic portion of the questionnaire. Remaining samples will be taken 30 and $60 \mathrm{~min}$ after questionnaire completion. Whole saliva samples will be collected in a $2 \mathrm{ml}$ microcentrifuge tube using a Saliva Collection Aid (Salimetrics, State College, PA). During data collection, salivary samples will be stored on dry ice in a cooler and then transferred immediately to a lab where samples were stored at $-80^{\circ} \mathrm{C}$ until analysis. Anonymized salivary data will be sent to Salimetrics in Carlsbad, CA for analysis, then returned.

Alcohol use will be assessed by a change in the frequency of alcohol use and hazardous alcohol use using the Alcohol Use Disorders Identification Test (AUDIT), a 10-item self-report measure developed by the World Health Organization for detecting alcohol use problems [56, 57]. Sugar-sweetened drink consumption will be assessed by a change in how frequently participants consume beverages sweetened with sugar, honey or syrup using self-report questions. Secondary outcomes are psychological stress symptomology, physiologic stress symptomology, social dislocation, and coping behaviour, which will be examined using the constructs and measures outlined in Tables 1 and 2 .

\section{Sample size}

A sample size calculation could not be estimated given the interventions proposed are novel for the population under study (Indigenous and non-Indigenous adults living in a small city in a rural area who engage in one or more cancer-risk behaviours). The sample size was selected in consultation with facilitators for the interventions, who indicated that 20-25 participants would be an effective group size to work with, and recognizing that each intervention must be run separately for males and females in keeping with cultural protocols recommended by Indigenous Elders and stakeholders.

\section{Statistical analysis}

For prediction of cancer-risk behaviour at 1 and 6 months post-intervention, participants will be included in the analysis if they have completed $50 \%$ of the intervention they are assigned to and have completed followup data collection for the specific time point. We will utilize a repeated-measure, mixed-model approach in order to identify significant changes in the main outcome variables between the four groups, stratified by gender and Indigenous/non-Indigenous status. Differences in baseline PTSD symptoms severity will be considered to acknowledge nonlinear treatment effects between participants at $t_{1}$. Potential confounding variables, such as exposure to potentially traumatizing events during the course of the intervention, will be used as covariates. Pearson's Chi-square test and Fisher's exact test will be used to assess the relationship between baseline characteristics and non-participation in the intervention and postintervention data collection time points. Missing data will be handled using listwise deletion. All analyses will be performed using STATA and R statistics. The anonymized quantitative dataset analyzed during the current study will be available upon reasonable request to Dr. Cheryl Currie between Jan 1, 2023 and Dec 31, 2025.

\section{Data security and management}

Microsoft Access is being used to manage and track participants using unique IDs assigned to each participant when they enroll in the study. Only the study team has 
Table 2 Study biomarkers

\begin{tabular}{|c|c|c|c|c|}
\hline Biomarkers & Source & Function & Measurement Procedure & Analysis \\
\hline \multicolumn{5}{|l|}{ 1. Immune } \\
\hline CRP & Saliva & Inflammatory marker. & Passive drool method ${ }^{a}$ & Lab analysis ${ }^{b}$ \\
\hline Secretory $\lg A$ & Saliva & $\begin{array}{l}\text { Immune function of mucous } \\
\text { membranes. }\end{array}$ & Passive drool & Lab analysis \\
\hline $\mathrm{IL}-1 \beta$ & Saliva & Pro-inflammatory cytokine & Passive drool & Lab analysis \\
\hline IL-6 & Saliva & $\begin{array}{l}\text { Pro- and anti-inflammatory } \\
\text { cytokine }\end{array}$ & Passive drool & Lab analysis \\
\hline IL-8 & Saliva & Pro-inflammatory cytokine & Passive drool & Lab analysis \\
\hline TNF a & Saliva & Pro-inflammatory cytokine & Passive drool & Lab analysis \\
\hline \multicolumn{5}{|l|}{ 2. Neuroendocrine } \\
\hline DHEA-S & Saliva & Stress-response marker & Passive drool & Lab analysis \\
\hline \multicolumn{5}{|l|}{ 3. Metabolic } \\
\hline BMl & & $\begin{array}{l}\text { Health-risk indicator for } \\
\text { cardiometabolic disease }\end{array}$ & $\begin{array}{l}\text { Height and weight will be measured } \\
\text { once, to the nearest } 0.5 \mathrm{~cm} \text { and } 0.1 \mathrm{~kg} \text {, } \\
\text { using a Health } O \text { Meter mechanical } \\
\text { beam scale and stadiometer. }\end{array}$ & $\begin{array}{l}\text { Participant's weight will be } \\
\text { divided by their height. }\end{array}$ \\
\hline WC & Iliac crest & $\begin{array}{l}\text { Health-risk indicator for } \\
\text { cardiometabolic disease }\end{array}$ & $\begin{array}{l}\text { WC will be measured twice at the top } \\
\text { of the iliac crest, to the nearest } 0.5 \mathrm{~cm} \text {. }\end{array}$ & The two measures will be averaged. \\
\hline \multicolumn{5}{|l|}{ 4. Cardiovascular } \\
\hline BP & Brachial artery & Pressure of blood in the arteries & $\begin{array}{l}\text { Resting systolic and diastolic blood } \\
\text { pressure will be measured using a Life } \\
\text { Source automated sphygmomanometer. } \\
\text { Participants will be seated and resting } \\
\text { quietly for } 3 \text { measurements. }\end{array}$ & $\begin{array}{l}\text { The first reading will be discarded. } \\
\text { The second and third readings } \\
\text { will be averaged. }\end{array}$ \\
\hline$H R$ & Brachial Pulse & $\begin{array}{l}\text { Estimate of cardiovascular } \\
\text { fitness and heart function }\end{array}$ & $\begin{array}{l}\text { Resting heart rate will be measured using } \\
\text { a Life Source automated sphygmomanometer. } \\
\text { Participants will be seated and resting quietly } \\
\text { for } 3 \text { measurements. }\end{array}$ & $\begin{array}{l}\text { The first reading will be discarded. } \\
\text { The second and third readings will } \\
\text { be averaged. }\end{array}$ \\
\hline Uric Acid & Saliva & $\begin{array}{l}\text { Associated with cardiovascular } \\
\text { responses to stress }\end{array}$ & Passive drool & Lab analysis \\
\hline \multicolumn{5}{|l|}{ Tobacco Use } \\
\hline Cotinine & Saliva & $\begin{array}{l}\text { Biomarker for exposure to } \\
\text { tobacco smoke }\end{array}$ & Passive drool & Lab analysis \\
\hline
\end{tabular}

CRP C-reactive protein, IL-1 Beta Interleukin-1 Beta, IL-6 Interleukin-6, IL-8 Interleukin-8, TNF a Tumor necrosis factor alpha, DHEA-S Dehydroepiandrosterone, BMI Body Mass index, WC Waist Circumference, BP Blood Pressure, HR Heart Rate. ${ }^{\text {T}}$ Three samples will be collected in office during a 90 -min participant appointment. Using a saliva collection aid, each participant will be given a 2-min time window to fill as much of one $2 \mathrm{ml}$ cryovial as possible. If the participant fills the cryovial in less than $2 \mathrm{~min}$, the time to completion will be noted on the vial. The first sample will be discarded and the other two will be sent to Salimetrics for analysis. ${ }^{b}$ For DHEA-S, the two samples will be pooled for analysis. The second saliva sample will be used for the analysis of all other biomarkers. The weight of the sample will be used to adjust for flow rate

access to this password protected database stored on a secure University of Lethbridge computer drive accessible only to the team. The questionnaire package is completed by participants during in-person data collection appointments using an iPad and a secure account with Qualtrics Inc. Qualtrics complies with the EU-U.S. Privacy Shield policies. All team members have signed confidentiality agreements. Signed consent forms are kept in a locked cabinet inside a locked room at the University of Lethbridge, separate from the master list linking participant identifiers to participant names, which will only be accessible by the PI. Data will be maintained for 10 years, and then shredded or deleted. Participants are informed of study risks in the consent form. Data monitoring will be the responsibility of the investigators.

\section{Safety measures}

All interventions will include a licensed and experienced counsellor present in the sessions. Counsellors will regularly check in with the Primary Investigator and each other across the course of the study. Significant issues will be brought to the attention of the Health Research Ethics Board of Alberta Cancer Committee. All participants will receive a brochure created for this project that outlines all available mental health resources available for the participant. 


\section{Ethics and dissemination}

This study has received ethics approval from the Health Research Ethics Board of Alberta Cancer Committee; important protocol modifications will be reviewed by this Committee. The trial will be conducted in compliance with this study protocol, the Tri-Council Policy Statement: Ethical Conduct for Research Involving Humans (TCPS 2) and Good Clinical Practice (GCP) [58]. Findings will be disseminated at regional and international conferences, in peer-reviewed journals, and through popular media. The PI will ensure that authors on manuscripts meet authorship criteria as defined by the International Committee of Medical Journal Editors. Professional medical writers will not be used in this study.

\section{Current trial status}

Recruitment of participants started in April 2019. Primary data analysis will begin Spring 2020. The last participant is expected to reach the primary endpoint in late 2021.

\section{Discussion}

Social trauma is a common experience and may be a key driver of cancer-risk behaviours, particularly within Indigenous populations given the legacy of colonization. Randomized trials designed to assess the effectiveness of trauma-informed interventions that may reduce engagement in these behaviours within community-based populations are needed. This controlled outcome trial will examine trauma-informed psychotherapeutic and bodybased interventions for cancer-risk behaviour. These interventions were developed through extensive consultation with expert and public stakeholders. We will oversample Indigenous adults, with stratified analyses planned specifically for this population. Limitations include the inability to blind participants due to the nature of the intervention, and the potential for limited generalizability given all data will be collected from participants living in a small city in western Canada.

\footnotetext{
Abbreviations

ACEs: Adverse childhood experiences; AUDIT: Alcohol Use Disorders Identification Test; BDE-S: Brief Dissociative Experiences Scale; BGQ: Brief Grief Questionnaire; BMI: Body mass index; CRP: C-reactive protein; DBP: Diastolic blood pressure; DHEA-S: Dehydroepiandrosterone sulfate; DUDIT: Drug Use Disorders Identification Test; EOD: Experiences of discrimination; GCP: Good Clinical Practice; HLS: Historical Loss Scale; HPA: Hypothalamic-pituitaryadrenal; HR: Heart rate; IDC: Integrative drum circles; IPAQ: International Physical Activity Questionnaire; PSQI: Pittsburgh Sleep Quality Index; PTSD: post-traumatic stress disorder; RSES: Rosenberg Self Esteem Scale; SBP: Systolic blood pressure; SCS-SF: Self-Compassion Scale - Short form; SSQ: Social Support Questionnaire; TCPS 2: Tri-Council Policy Statement: Ethical Conduct for Research Involving Humans; TIY: Trauma-informed yoga; TNF a: Tumor necrosis factor alpha; VI: Vancouver Index; WC: Waist circumference
}

\section{Acknowledgements}

The authors wish to thank the clinical and community stakeholders who provided input on the development of the interventions for this project.

\section{Authors' contributions}

CC designed the study and drafted the manuscript. CC, JL, LS, LV, and MA initiated the study design, and EH and NP helped with implementation. CC and $\mathrm{J}$ are grant holders. All authors contributed to refinement of the study protocol, reviewed and provided feedback on the manuscript, and approved the final manuscript.

\section{Funding}

This study was funded by an operating grant from the Alberta Cancer Prevention Legacy Fund (role of study sponsor in study design, analysis, and interpretation: None).

\section{Availability of data and materials}

The dataset that will be analyzed for this study is available from the corresponding author on reasonable request.

\section{Ethics approval and consent to participate}

This study has received ethics approval from the Health Research Ethics Board of Alberta Cancer Committee (ID: HREBA.CC-18-0467). All participants will provide informed written consent to participate.

\section{Consent for publication \\ Not applicable}

\section{Competing interests}

The authors declare that they have no competing interests.

\section{Author details}

${ }^{1}$ Faculty of Health Sciences, University of Lethbridge, M3083 Markin Hall, 4401 University Drive, Lethbridge, AB T1K 3M4, Canada. 'Department of Kinesiology and Physical Education, University of Lethbridge, Lethbridge, Canada. ${ }^{3}$ Canadian Centre for Behavioural Neuroscience, University of Lethbridge, Lethbridge, Canada.

Received: 2 September 2019 Accepted: 16 September 2019 Published online: 29 October 2019

\section{References}

1. Lee PN, Forey BA, Coombs KJ. Systematic review with meta-analysis of the epidemiological evidence in the 1900s relating smoking to lung cancer. BMC Cancer [Internet]. 2012;12(1):385 [cited 2018 Nov 9]. Available from: http://www.ncbi.nlm.nih.gov/pubmed/22943444

2. Ordóñez-Mena JM, Schöttker B, Mons U, Jenab M, Freisling H, Bueno-deMesquita B, et al. Quantification of the smoking-associated cancer risk with rate advancement periods: meta-analysis of individual participant data from cohorts of the CHANCES consortium. BMC Med [Internet]. 2016;14(1):62 [cited 2018 Nov 9]. Available from: http://www.ncbi.n/m.nih.gov/pubmed/2 7044418.

3. Bérubé S, Lemieux J, Moore L, Maunsell E, Brisson J. Smoking at time of diagnosis and breast cancer-specific survival: new findings and systematic review with meta-analysis. Breast Cancer Res [Internet]. 2014;16(2):3402 [cited 2018 Nov 9]. Available from: http://www.ncbi.nlm.nih.gov/pubmed/24 745601

4. Sinha DN, Abdulkader RS, Gupta PC. Smokeless tobacco-associated cancers: A systematic review and meta-analysis of Indian studies. Int J Cancer [Internet]. 2016;138(6):1368-79 [cited 2018 Nov 9]. Available from: http:// www.ncbi.nlm.nih.gov/pubmed/26443187.

5. Chang CM, Corey CG, Rostron BL, Apelberg BJ. Systematic review of cigar smoking and all cause and smoking related mortality. BMC Public Health [Internet]. 2015;15(1):390 [cited 2018 Nov 9]. Available from: http://www. ncbi.nlm.nih.gov/pubmed/25907101.

6. Bagnardi V, Blangiardo M, La Vecchia C, Corrao G. Alcohol consumption and the risk of cancer: a meta-analysis. Alcohol Res Heal. 2001;25:263-70.

7. de Menezes RF, Bergmann A, LCS T. Alcohol consumption and risk of cancer: a systematic literature review. Asian Pac J Cancer Prev [Internet]. 2013;14(9):4965-72 [cited 2018 Nov 9].Available from: http://www.ncbi.nlm. nih.gov/pubmed/24175760.

8. Rehm J. The risks associated with alcohol use and alcoholism. Alcohol Res Health [Internet]. $2011 ; 34(2): 135-143$. [cited 2018 Nov 9]. Available from: http://www.ncbi.nlm.nih.gov/pubmed/22330211. 
9. Nelson DE, Jarman DW, Rehm J, Greenfield TK, Rey G, Kerr WC, et al. Alcohol-attributable cancer deaths and years of potential life lost in the United States. Am J Public Health [Internet]. 2013;103(4):641-8 [cited 2018 Nov 9]. Available from: http://www.ncbi.n/m.nih.gov/pubmed/23409916.

10. Shield KD, Soerjomataram I, Rehm J. Alcohol use and breast cancer: a critical review. Alcohol Clin Exp Res [Internet]. 2016;40(6):1166-81 [cited 2018 Nov 9]. Available from: http://www.ncbi.nlm.nih.gov/pubmed/27130687.

11. Rehm J, Shield KD. Global alcohol-attributable deaths from cancer, liver cirrhosis, and injury in 2010. Alcohol Res [Internet]. 2013;35(2):174-83 [cited 2018 Nov 9]. Available from: http://www.ncbi.nlm.nih.gov/pubmed/24 881325

12. Makimoto $\mathrm{K}$, Oda $\mathrm{H}$, Higuchi S. Is heavy alcohol consumption an attributable risk factor for cancer-related deaths among Japanese men? Alcohol Clin Exp Res [Internet]. 2000;24(3):382-5 [cited 2018 Nov 9]; Available from: http://www.ncbi.nlm.nih.gov/pubmed/10776681.

13. Fuchs MA, Sato K, Niedzwiecki D, Ye X, Saltz LB, Mayer RJ, et al. Sugarsweetened beverage intake and cancer recurrence and survival in CALGB 89803 (Alliance). Moschetta A, editor. PLoS One [Internet]. 2014;9(6):e99816 [cited 2018 Nov 9]. Available from: https://dx.plos.org/10.1371/journal.pone. 0099816.

14. Larsson SC, Giovannucci EL, Wolk A. Sweetened beverage consumption and risk of biliary tract and gallbladder cancer in a prospective study. J Natl Cancer Inst [Internet]. 2016;108(10):djw125 [cited 2018 Nov 9]. Available from: https://academic.oup.com/jnci/article-lookup/doi/10.1093/jnci/djw125.

15. Gallagher EJ, LeRoith D. Obesity and diabetes: The increased risk of cancer and cancer-related mortality. Physiol Rev [Internet]. 2015;95(3):727-48 [cited 2018 Nov 9]. Available from: http://www.ncbi.nlm.nih.gov/pubmed/26084689.

16. Imamura F, O'Connor L, Ye Z, Mursu J, Hayashino Y, Bhupathiraju SN, et al. Consumption of sugar sweetened beverages, artificially sweetened beverages, and fruit juice and incidence of type 2 diabetes: systematic review, meta-analysis, and estimation of population attributable fraction. BMJ [Internet]. 2015;351:h3576 [cited 2018 Nov 9]. Available from: http:// www.ncbi.nlm.nih.gov/pubmed/26199070.

17. Navarrete-Muñoz EM, Wark PA, Romaguera D, Bhoo-Pathy N, Michaud D, Molina-Montes E, et al. Sweet-beverage consumption and risk of pancreatic cancer in the European Prospective Investigation into Cancer and Nutrition (EPIC). Am J Clin Nutr [Internet]. 2016;104(3):760-8 [cited 2018 Nov 9]. Available from: https://academic.oup.com/ajcn/article/104/3/760/4564724.

18. Kippen $R$, James E, Ward B, Buykx P, Shamsullah A, Watson W, et al. Identification of cancer risk and associated behaviour: implications for social marketing campaigns for cancer prevention. BMC Cancer [Internet]. 2017; 17(1):550 [cited 2019 Aug 9]. Available from: http://www.ncbi.nlm.nih.gov/ pubmed/28818048.

19. Stead M, Angus K, Langley T, Katikireddi SV, Hinds K, Hilton S, et al. Mass media to communicate public health messages in six health topic areas: a systematic review and other reviews of the evidence [Internet]. Mass media to communicate public health messages in six health topic areas: a systematic review and other reviews of the evidence. NIHR Journals Library; 2019 [Cited 2019 Aug 9]. Available from: http://www.ncbi.n/m.nih.gov/ pubmed/31046212.

20. Rose G. Sick individuals and sick populations. Int J Epidemiol. 2001;30:427-32.

21. Alexander $B$. The globalization of addiction: a study in poverty of the spirit. Oxford, UK: Oxford University Press; 2010.

22. Ports KA, Holman DM, Guinn AS, Pampati S, Dyer KE, Merrick MT, et al. Adverse childhood experiences and the presence of cancer risk factors in adulthood: a scoping review of the literature from 2005 to 2015. J Pediatr Nurs [Internet]. 2019:44:81-96 [cited 2019 Jul 9]. Available from: https:// www.sciencedirect.com/science/article/pii/S088259631830280X.

23. Felitti VJ, Anda RF, Nordenberg D, Williamson DF, Spitz AM, Edwards V, et al. Relationship of childhood abuse and household dysfunction to many of the leading causes of death in adults: the Adverse Childhood Experiences (ACE) Study. Am J Prev Med [Internet]. 1998;14(4):245-58 [cited 2018 Aug 22]. Available from: https://linkinghub.elsevier.com/retrieve/pii/S0749379798000178.

24. Afifi TO, Mather A, Boman J, Fleisher W, Enns MW, MacMillan H, et al. Childhood adversity and personality disorders: Results from a nationally representative population-based study. J Psychiatr Res [Internet]. 2011;45(6): 814-22 [cited 2019 May 13]Available from: https://linkinghub.elsevier.com/ retrieve/pii/S0022395610003262.

25. McDonald SW, Kingston D, Bayrampour H, Tough S. Adverse childhood experiences in Alberta, Canada: a population based study. Med Res Arch. 2015;3:1-18.
26. Dube SR, Anda RF, Felitti VJ, Chapman DP, Williamson DF, Giles WH. Childhood Abuse, Household Dysfunction, and the Risk of Attempted Suicide Throughout the Life Span. JAMA [Internet]. 2001;286(24):3089 [cited 2018 Aug 22]. Available from: http://jama.jamanetwork.com/article. aspx?doi=10.1001/jama.286.24.3089.

27. Dube SR, Anda RF, Felitti VJ, Edwards VJ, Williamson DF. Exposure to Abuse, Neglect, and Household Dysfunction Among Adults Who Witnessed Intimate Partner Violence as Children: Implications for Health and Social Services. Violence Vict [Internet]. 2002;17(1):3-17 [cited 2019 May 13]. Available from: http://connect.springerpub.com/lookup/doi/10.1891/vivi.1 7.1.3.33635.

28. Dube SR, Felitti VJ, Dong M, Chapman DP, Giles WH, Anda RF. Childhood Abuse, Neglect, and Household Dysfunction and the Risk of Illicit Drug Use: The Adverse Childhood Experiences Study. Pediatrics [Internet]. 2003;111(3): 564-72 [cited 2018 Aug 22]Available from: http://pediatrics.aappublications. org/cgi/doi/10.1542/peds.111.3.564.

29. Sinclair M. Honouring the truth, reconciling for the future: summary of the final report of the truth and reconciliation Commission of Canada [Internet] Truth and Reconciliation Commission of Canada: Ottawa; 2015. Available from: http://www.trc.ca/websites/trcinstitution/index.php?p=3

30. Currie CL, Wild TC, Schopflocher D, Laing L. Racial discrimination, posttraumatic stress and prescription drug problems among aboriginal Canadians. Can J Public Heal. 2015;106(6):e382-7.

31. Currie $\mathrm{CL}$, Wild TC. Adolescent use of prescription drugs to get high in Canada. Can J Psychiatr. 2012 Dec;57(11):745-51.

32. Currie, CL, Copeland, JL, Metz GA, Chiefmoon-Riley, K, Davies C. Past-year racial discrimination and allostatic load among Indigenous adults in Canada: the role of cultural continuity. Psychosom Med. 2019; In press.

33. van der Kolk BA. The neurobiology of childhood trauma and abuse. Child Adolesc Psychiatr Clin N Am [Internet]. 2003;12(2):293-317 [cited 2018 Nov 9]. Available from: http://linkinghub.elsevier.com/retrieve/pii/S1056499303 000038.

34. Williamson JB, Porges EC, Lamb DG, Porges SW. Maladaptive autonomic regulation in PTSD accelerates physiological aging. Front Psychol [Internet]. 2014;5:1571 [cited 2019 Aug 22]. Available from: http://www.ncbi.nlm.nih. gov/pubmed/25653631.

35. Diseth $\mathrm{TH}$. Dissociation in children and adolescents as reaction to trauma an overview of conceptual issues and neurobiological factors. Nord J Psychiatry [Internet]. 2005;59(2):79-91 [cited 2019 Aug 19], Available from: http://www.ncbi.nlm.nih.gov/pubmed/16195104.

36. Franzoni E, Gualandi S, Caretti V, Schimmenti A, Di Pietro E, Pellegrini G, et al. The relationship between alexithymia, shame, trauma, and body image disorders: investigation over a large clinical sample. Neuropsychiatr Dis Treat [Internet]. 2013;9:185-93 [cited 2019 Aug 19]. Available from: http://www.ncbi.nlm.nih.gov/pubmed/23550168.

37. Choi KR, Ford JD, Briggs EC, Munro-Kramer ML, Graham-Bermann SA, Seng JS. Relationships between maltreatment, posttraumatic symptomatology, and the dissociative subtype of PTSD among adolescents. J Trauma Dissociation [Internet]. 2019;20(2):212-27 [cited 2019 Aug 19]. Available from: http://www.ncbi.nlm.nih.gov/pubmed/30714854.

38. Ogden P, Minton K, Pain C. Trauma and the body: a sensorimotor approach to psychotherapy [Internet]. W W Norton \& Co: New York, NY; 2006. Available from: https://psycnet.apa.org/record/2006-12273-000

39. Emerson D. Trauma-sensitive yoga in therapy : bringing the body into treatment. WW Norton; 2015

40. Balasubramaniam M, Telles S, Doraiswamy PM. Yoga on our minds: a systematic review of Yoga for neuropsychiatric disorders. Front Psychiatry [Internet]. 2013;3:117 [cited 2019 Aug 19]. Available from: http://journal. frontiersin.org/article/10.3389/fpsyt.2012.00117/abstract.

41. Macy RJ, Jones E, Graham LM, Roach L. Yoga for trauma and related mental health problems: a meta-review with clinical and service recommendations. Trauma, Violence, Abus. 2018;19(1):35-57.

42. Streeter CC, Gerbarg PL, Saper RB, Ciraulo DA, Brown RP. Effects of yoga on the autonomic nervous system, gamma-aminobutyric-acid, and allostasis in epilepsy, depression, and post-traumatic stress disorder. Med Hypotheses [Internet]. 2012;78(5):571-9 [cited 2019 Aug 13]. Available from: https:// linkinghub.elsevier.com/retrieve/pii/S0306987712000321.

43. van der Kolk BA, Stone L, West J, Rhodes A, Emerson D, Suvak M, et al. Yoga as an Adjunctive Treatment for Posttraumatic Stress Disorder. J Clin Psychiatry [Internet]. 2014;75(06):e559-65 [cited 2019 Aug 13]. Available from: http://article.psychiatrist.com/?ContentType=START\&ID=10008683. 
44. Tague DB. Effect of improvisational group drumming versus general music therapy versus activity therapy on mood, session behaviors and transfer Behaviors of in-patient psychiatric individuals [Internet]. Florida State University Electronic Thesis, Treaties and Dissertations, Paper 5220; 2012. Available from: https://search.proquest.com/docview/1095642436?pqorigsite $=$ gscholar

45. Bittman BB, Snyder C, Bruhn KT, Liebfreid F, Stevens CK, Westengard J, et al. Recreational music-making: an integrative group intervention for reducing burnout and improving mood states in first year associate degree nursing students: insights and economic impact. Int J Nurs Educ Scholarsh. 2004;1: Article12.

46. Carr C, d'Ardenne P, Sloboda A, Scott C, Wang D, Priebe S. Group music therapy for patients with persistent post-traumatic stress disorder - an exploratory randomized controlled trial with mixed methods evaluation. Psychol Psychother Theory Res Pract. 2012 Jun;85(2):179-202.

47. Smith C, Viljoen JT, McGeachie L. African drumming: a holistic approach to reducing stress and improving health? J Cardiovasc Med. 2014 Jun;15(6): 441-6.

48. Dunbar RIM, Kaskatis K, MacDonald I, Barra V. Performance of music elevates pain threshold and positive affect: implications for the evolutionary function of music. Evol Psychol. 2012 Oct;10(4):147470491201000.

49. Wachi M, Koyama M, Utsuyama M, Bittman BB, Kitagawa M, Hirokawa K. Recreational music-making modulates natural killer cell activity, cytokines, and mood states in corporate employees. Med Sci Monit. 2007 Feb;13(2): CR57-70.

50. Koyama M, Wachi M, Utsuyama M, Bittman B, Hirokawa K, Kitagawa M. Recreational music-making modulates immunological responses and mood states in older adults. J Med Dent Sci. 2009 Jun;56(2):79-90.

51. Bittman BB, Berk LS, Felten DL, Westengard J, Simonton OC, Pappas J, et al. Composite effects of group drumming music therapy on modulation of neuroendocrine-immune parameters in normal subjects. Altern Ther Health Med. 2001 Jan;7(1):38-47.

52. Fancourt D, Perkins R, Ascenso S, Carvalho LA, Steptoe A, Williamon A. Effects of group drumming interventions on anxiety, depression, social resilience and inflammatory immune response among mental health service users. Quinn TJ, editor. PLoS One. 2016;11(3):e0151136.

53. Atkinson J. The drum code: living well between the beats. Calgary, AB: Create Space Publishing; 2017.

54. Hull A. Drum circle facilitation: building community through rhythm. Village Music Circles: Santa Cruz, CA; 2006.

55. Paoletti P, Fornai E, Maggiorelli F, Puntoni R, Viegi G, Carrozzi L, et al. Importance of baseline cotinine plasma values in smoking cessation: results from a double-blind study with nicotine patch. Eur Respir J. 1996;9:643-51.

56. Fleming MF, Barry KL, MacDonald R. The alcohol use disorders identification test (AUDIT) in a college sample. Int J Addict. 1991;26:1173-85.

57. Allen JP, Litten RZ, Fertig JB, Babor T. A review of research on the alcohol use disorders identification test (AUDIT). Alcohol Clin Exp Res. 1997;21:613-9.

58. Government of Canada IAP on RE. Interagency Advisory Panel on Research Ethics [Internet]. 2014. Available from: http://www.pre.ethics.gc.ca/eng/ policy-politique/initiatives/tcps2-eptc2/Default/

\section{Publisher's Note}

Springer Nature remains neutral with regard to jurisdictional claims in published maps and institutional affiliations.

Ready to submit your research? Choose BMC and benefit from:
- fast, convenient online submission
- thorough peer review by experienced researchers in your field
- rapid publication on acceptance
- support for research data, including large and complex data types
- gold Open Access which fosters wider collaboration and increased citations
- maximum visibility for your research: over 100M website views per year
At BMC, research is always in progress.
Learn more biomedcentral.com/submissions

